\title{
Emerging methods to study bacteriophage infection at the single-cell level
}

\author{
Vinh T. Dang ${ }^{1}$ and Matthew B. Sullivan ${ }^{1,2}$ * \\ ' Department of Ecology and Evolutionary Biology, University of Arizona, Tucson, AZ, USA \\ ${ }^{2}$ Department of Molecular and Cellular Biology, University of Arizona, Tucson, AZ, USA
}

\section{Edited by:}

Stefan Bertilsson, Uppsala University, Sweden

\section{Reviewed by:}

Andreas Schramm, Aarhus University, Denmark

Télesphore Sime-Ngando, Centre National de la Recherche, France

${ }^{*}$ Correspondence:

Matthew B. Sullivan, Department of Ecology and Evolutionary Biology,

University of Arizona, Tucson Marine Phage Lab, 1007 E Lowell Street,

Tucson, AZ 85721, USA

e-mail:mbsull@email.arizona.edu
Bacteria and their viruses (phages) are abundant across diverse ecosystems and their interactions influence global biogeochemical cycles and incidence of disease. Problematically, both classical and metagenomic methods insufficiently assess the host specificity of phages and phage-host infection dynamics in nature. Here we review emerging methods to study phage-host interaction and infection dynamics with a focus on those that offer resolution at the single-cell level. These methods leverage ever-increasing sequence data to identify virus signals from single-cell amplified genome datasets or to produce primers/probes to target particular phage-bacteria pairs (digital PCR and phageFISH), even in complex communities. All three methods enable study of phage infection of uncultured bacteria from environmental samples, while the latter also discriminates between phagehost interaction outcomes (e.g., lytic, chronic, lysogenic) in model systems. Together these techniques enable quantitative, spatiotemporal studies of phage-bacteria interactions from environmental samples of any ecosystem, which will help elucidate and predict the ecological and evolutionary impacts of specific phage-host pairings in nature.

Keywords: phage-bacteria interaction, infection strategy, single-cell amplified genome, digital PCR, phageFISH

\section{PHAGE INFECTION OUTCOMES REMAIN LARGELY UNKNOWN FOR UNCULTURED HOSTS}

Phages and their bacterial hosts are abundant across diverse ecosystems wherever investigated, including fresh water (Hennes and Simon, 1995), sea water (Bergh, 1989; Fuhrman, 1999; Wommack and Colwell, 2000), sediment (Danovaro et al., 2002), soil (Ashelford et al., 2003; Salifu et al., 2013), and the human mouth, gut, and respiratory tract (Hitch et al., 2004; Letarov and Kulikov, 2009; Willner et al., 2009; Stern et al., 2012; Reyes etal., 2013). Phages influence global biogeochemical cycling by manipulating host populations through mortality, horizontal gene transfer, and viral metabolic reprogramming. First, phage-induced lysis of microbial cells releases organic matter and contributes to carbon, nitrogen, and phosphorus cycling (Shelford et al., 2012; Jover et al., 2014). Second, virus-mediated horizontal gene transfer can have major implications on host evolutionary trajectories. In the oceans, cyanobacterial viruses (cyanophages) have captured core photosystem genes that alter the evolutionary trajectory of these globally distributed photosystems (Lindell et al., 2004; Sullivan et al., 2006). In medicine, prophage-encoded virulence factors routinely transform hosts into pathogens (e.g., Clostridium botulinum, Corynebacterium diphtheria, Streptococcus pyogenes, and Vibrio cholera) that cause diseases in humans (Davis et al., 1999; Wagner and Waldor, 2002; Broudy and Fischetti, 2003; Brussow etal., 2004; Mokrousov, 2009). Finally, virus-encoded 'auxiliary metabolic genes' (AMGs, sensu; Breitbart et al., 2007) can directly alter the metabolic processing of infected cells away from their uninfected states with known implications for photosynthesis (Mann etal., 2003; Dammeyer et al., 2008; Sharon et al., 2009; Thompson et al., 2011, and as above), nearly all of central carbon metabolism (Hurwitz et al., 2013b), and coupled carbon and sulfur cycling (Anantharaman et al., 2014; Roux et al., 2014).

Despite the apparent importance of virus-host interaction outcomes to ecosystem function, our knowledge has been largely bottlenecked by cultivation and technical limitations. Only a fraction $(<1 \%)$ of microbes in nature grow under typical laboratory conditions (Rappe and Giovannoni, 2003), and few of the 50 known bacterial phyla have cultured phages, largely dominated by three phyla including Cyanobacteria (e.g., Suttle and Chan, 1993; Lu etal., 2001; Sullivan et al., 2003), Proteobacteria (e.g., Ceyssens etal., 2010; Fogg et al., 2011; Wittmann et al., 2014), and Bacteroidetes (e.g., Holmfeldt et al., 2013, 2014). Such model systems are inordinately valuable to test experimental hypotheses and represent the gold standard for developing mechanistic understanding of particular phage-host infection dynamics and outcomes. However, even while new and ecologically abundant phage-host systems are coming into culture (e.g., SAR11 and SAR116 phages; Kang et al., 2013; Zhao et al., 2013), it is unlikely that cultivation-based approaches will be able to map the immense network of phage-host interactions in natural ecosystems.

In addition to establishing reference data representing some fraction of the virosphere, there is a need to better quantify the relative importance of phage-host interaction outcomes in nature. The most commonly described phage life cycles are lytic and lysogenic. Lytic phages infect cells and use host machinery for replicating their nucleic acids (Young, 1992; Catalão etal., 2013). After self-assembly of capsid proteins with their DNA/RNA genomes, host cells are lysed to release 10-100s of progeny into the extracellular environment which then seek to infect other cells. In contrast, temperate phages infect a cell and then either continue with a lytic infection or enter lysogeny whereby the 
phage chromosome is maintained either integrated in the host's chromosome or extrachromosomally (Jiang and Paul, 1998; Little, 2005). Under certain conditions (e.g., UV radiation, chemicals, nutrients), temperate phages are induced into the lytic cycle to produce progeny phages and lyse the cells. Lytic phages impact the ecosystem by reducing susceptible host abundances and releasing organic matter from lysed cells. Lysogeny can improve host fitness (Anderson et al., 2011a), including increased growth rate (Edlin et al., 1975), resistance against superinfection by other phages (Bossi et al., 2003), resilience to stressors (Wang et al., 2010), and virulence of a host microbe to its eukaryotic host (Fortier and Sekulovic, 2013).

Other than the lytic and lysogenic cycles, phages are also known to chronically infect their hosts or enter pseudolysogeny. Chronically infecting phages produce progeny that are slowly budded off the cell or passed down to daughter cells without cell lysis at any time (Weinbauer, 2004; Díaz-Muñoz and Koskella, 2014). Similarly, the pseudolysogenic state (sometimes known as "carrier state"), which is poorly understood, implies neither integration of the phage genome into the host genome nor host cell lysis (Weinbauer, 2004; Lood and Collin, 2011; Díaz-Muñoz and Koskella, 2014) and might also be thought of as a chronic infection. This infection strategy is believed to help phages persist in hosts when there is a lack of nutrients to support normal microbial growth. However, both phenomena are insufficiently described in natural communities, and their ecological impacts remain quantitatively unknown at least partly due to the lack of suitable methods.

This leaves three fundamental questions unanswered: (1) who infects whom, (2) how many percent of microbial cells are infected at a particular time point, and (3) how does infection progress over time or under different growing conditions. Fortunately, some of these much-needed methods are beginning to emerge. These include viral tagging (Deng et al., 2012) and viral tagged metagenomics (Deng et al., 2014), large-insert fosmid library screening (Mizuno et al., 2013), and in silico linkages derived from sequence composition (Canchaya et al., 2003; Paul, 2008; Akhter et al., 2012) or CRISPR identification (Andersson and Banfield, 2008; Anderson et al., 2011b; Weinberger et al., 2012). In addition, the sequence composition-independent approach of metagenomic analysis (Albertsen et al., 2013) facilitates the recovery of more complete genomes of bacteria, including ones of rare abundance, to allow mining of viral signals at the population level. While all these methods are incredibly powerful for examining population genomic signals across datasets, they lack the ability to develop a single-cell perspective on virus-host interaction outcomes.

Here we review emerging single-cell methods to study phage diversity and infection outcomes with a focus on those that also provide access to uncultured hosts. These methods leverage the sequence information increasingly becoming available to mine virus signals from single-cell genomic datasets and/or to design probes and primers to target particular phage-host groups over time and space in complex communities.

\section{MINING THE "VIRUS" FROM UNCULTIVATED SINGLE-CELL AMPLIFIED GENOMES (SAGs)}

Microbial ecologists are rising to the challenge of understanding the 'unseen majority' (Whitman et al., 1998) or 'microbial dark matter' (Rinke et al., 2013) by sequencing single-cell amplified genomes (SAGs). This process works by isolating individual cells from an environmental sample (e.g., micro-pipetting, fluorescence-activated cell sorting, microfluidic cell separating), screening those cells using marker gene sequencing, and then amplifying and sequencing the DNA from cells of interest (Lasken, 2012; Macaulay and Voet, 2014). Researchers are generally interested in what metabolisms are associated with this sequence data to pair up known metabolisms with their organismal "owners". However, such data also represents a treasure trove for new virus discovery. For example, SAG analysis revealed a complete genome of single-stranded DNA virus associated with a cell of one clade, but not with two other marine picobiliphytes (Yoon et al., 2011).

Beyond general surveys, SAGs offer the opportunity for focused ecological and evolutionary study of particular phage-host pairs in nature, which represents a grand challenge in the field and is only achievable using cultures. For example, a recent study (Roux et al., 2014) in a model marine oxygen minimum zone targeted the phages of SUP05 bacteria, an uncultivated group critical in this environment for chemoautotrophy driven by coupled carbon and sulfur nutrient cycling (Wright et al., 2012). A total of 127 SUP05 SAGs were sequenced and mined for viral signal, leading to genomic reference sequences for 69 new phages (Roux et al., 2014). Distributions of detected phages across the SAGs suggested that about one-third of SUP05 cells were infected, with higher infection frequencies where cells are more active. Comparison of these new reference phage genomes to 189 viral or microbial metagenomic datasets suggested that the SUP05 phages were persistent over 3 years in the oxygen minimum zone, but endemic with little indication of the viruses occurring in any of the other datasets available for population-level analysis. Undoubtedly, as more microbial sequence data becomes available, SAGs will provide an invaluable resource for further mapping the virosphere and gaining ecological and evolutionary insight into specific phage-host interaction dynamics.

\section{LINKING VIRUSES TO THEIR HOSTS USING DIGITAL PCR}

Digital PCR was initially used to quantify the fraction of DNA molecules with mutations predefined in cancer cells (Vogelstein and Kinzler, 1999). Briefly, genomic DNA is diluted to extinction in microtiter plates (e.g., 96- or 384-well plates) so that individual templates can be separately PCR-amplified. This enables a rare mutant template to be detected from the mixture with sensitivity and accuracy higher than the $\sim 2$-fold detection limits possible with quantitative real-time PCR (Smith and Osborn, 2009; Baker, 2012). Based on a fluorescence measurement, the mutant signal can be distinguished from the wild-type by a loop sequence of fluorescent probe molecular beaconRED (MB-RED, 5'-Cy3-oligonucleotide probe-Dabcyl-3') that detects wild-type and mutant products as compared to an MBGREEN ( $5^{\prime}$-fluorescein-oligonucleotide probe-Dabcyl-3') probe that only recognizes wild-type template as mutations impede probe hybridization.

Application of microfluidic technology improves digital PCR (Ottesen etal., 2006; Marcy etal., 2007; Zare and Kim, 2010) by enabling larger-scale study (e.g., isolate and analyze single cells on a 765-chamber PCR array panel, where most chambers 
contain no or one cell; Figure 1A). When complemented with sequencing, microfluidic digital PCR has helped elucidate phagehost associations from environmental samples (e.g., termite hindgut; Tadmor etal., 2011), specifically answering two critical research questions in viral and microbial ecology: who infects whom, and what percent of particular host cells is infected by a particular phage. Pragmatically, the phage-host association is revealed by co-localized fluorescent signals (FAM and HEX for phage and host, respectively). PCR products of a phage conserved gene (e.g., terminase) hybridize to FAM-labeled probe while that of bacterial $16 \mathrm{~S}$ rRNA gene bind to HEX-labeled probe. Finally, phage and host can be identified by sequencing DNA retrieved from PCR array chambers with co-localized signals.

The critical step in applying microfluidic digital PCR to other systems is the design of appropriate primers. In the termite hindgut work (Tadmor etal., 2011), universal 16S rRNA primers and terminase primers were used to identify the host and phage, respectively. New primer sets can be designed by analyzing metagenomic datasets (e.g., use of Metagenome Cluster Analysis Tool; Tadmor et al., 2011) to identify lineage-specific marker genes for particular viral and microbial targets. The program CODEHOP (Rose et al., 2003) can then explore marker gene regions to design primers with minimal degeneracy and primer dimers, as well as melting temperature profiles similar to those of the bacterial rRNA universal primer set to enable co-amplification. Several sets of designed primers are then experimentally tested to optimize amplification performance and detection limit (e.g., <100 gene copies; Tadmor et al., 2011).

There are a few challenges for linking viruses to their hosts by microfluidic digital PCR. First, false positive signals can occur from multiple phage genes released from prematurely lysed cells, multiple bacterial 16S rRNA genes from cells adhered to the same chamber, or fluorescence signal spilled over from neighboring chambers (Tadmor et al., 2011). These issues can be circumvented by excluding chambers with multiple bacterial and/or viral signals, which notably rules out co-infections whose frequencies are largely unknown, and considering only chambers flanked by ones with no fluorescence in both channels. Alternatively, a barcoding strategy can be applied so that individual DNA template can be tagged with a unique barcode, amplified, and read by sequencing (Kinde et al., 2011). Second, the 765-chamber PCR array panel, while already a large increase in throughput, is still likely only a tiny sub-sample of naturally occurring diversity. One way forward would be adoption of droplet-based strategies (Hindson etal., 2011; Jones etal., 2014) to sort cells into nanoliter-sized droplets (QX100/QX200 Droplet Digital PCR System, Bio-Rad) where PCR could occur on scales of 10 s of $1000 \mathrm{~s}$
A

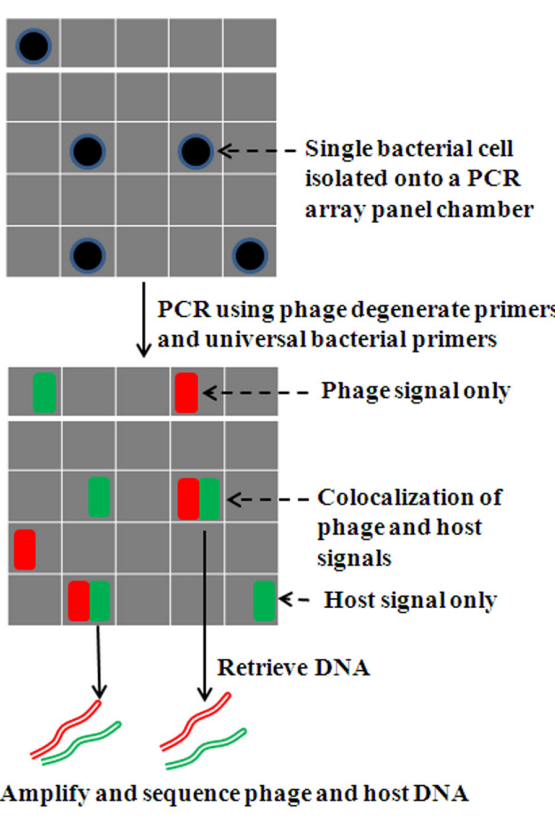

FIGURE 1 | Overview of procedures of single-cell experimental methods to examine phage-host interactions. (A) For microfluidic digital PCR, cells are sorted onto an array panel with the majority of chambers containing no or single cells (adapted from Tadmor et al., 2011). Concurrent amplification is carried out for both phage and bacterial marker genes. Co-localization of phage and bacterial signals is shown in FAM and HEX channels, respectively, with fluorescence in half of each PCR array chamber. (B) For phageFISH, the phage-host sample is either immobilized on $0.2 \mu \mathrm{m}$ filter membranes or

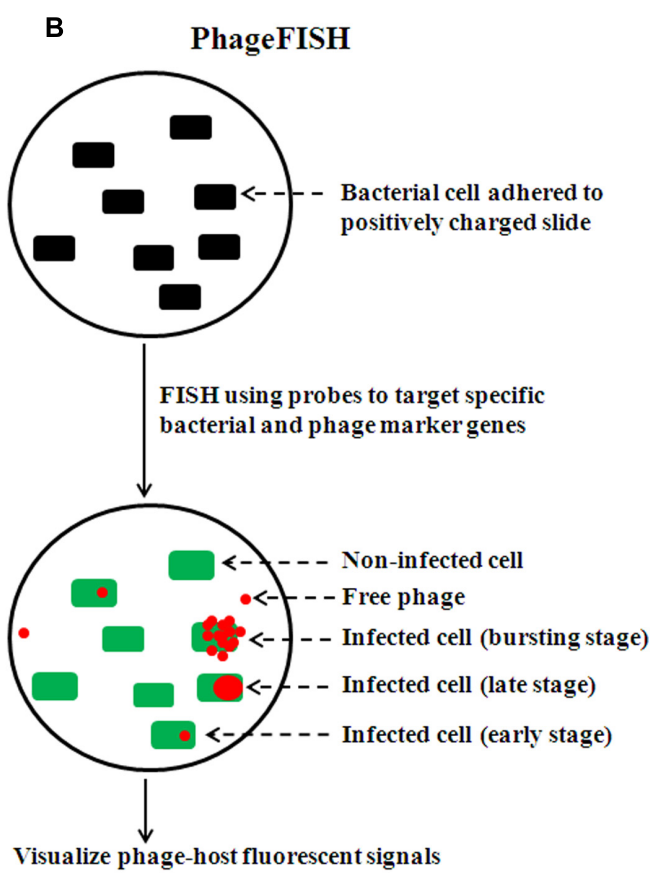

adhered to positively charged slides (adapted from Allers et al., 2013). A bacterial marker gene (16S rRNA) is detected by oligoprobes conjugated to horseradish peroxidase (HRP) molecules, which catalyze the deposition of many fluorescently labeled tyramides (e.g., green Alexa 488 ). Subsequently, the phage marker gene is detected by a set of double-stranded DNA probes (6-12) labeled with digoxigenin (DIG) molecules. DIG is then recognized by an antibody that is labeled with HRP molecule to catalyze the deposition of many fluorescently labeled tyramides (e.g., red Alexa595). 


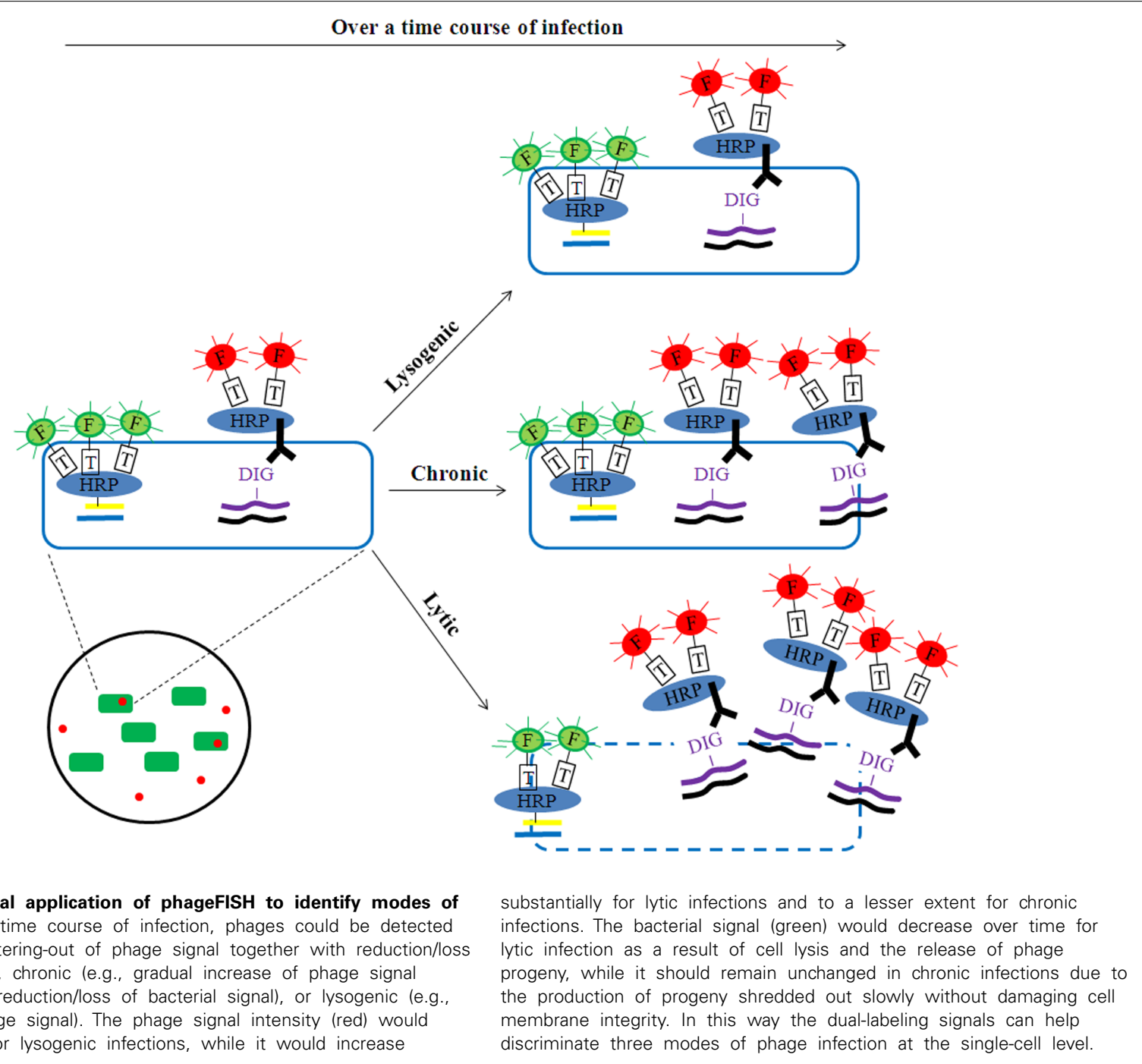

of reactions while leveraging automated fluidic systems. Such data scales would allow researchers to examine specific phagehost pairs with a very small fraction of cells and/or phages in environmental samples.

\section{LINKING AND VISUALIZING PHAGE-HOST INTERACTIONS USING FLUORESCENCE IN SITU HYBRIDIZATION}

Alternative to digital PCR-based methods, fluorescence in situ hybridization (FISH) methods offer an opportunity to examine specific phage-host interactions. GeneFISH (Moraru et al., 2010) was originally developed to detect cellular marker genes at the single-cell level. Briefly, microbial communities are collected (e.g., on $0.2 \mu \mathrm{m}$ membrane filters or positive-charged slides), and then probes are introduced to target a bacterial marker gene (e.g., 16s rRNA) and a biogeochemically relevant gene. Horseradish peroxidase (HRP) molecules linked to probes catalyze the deposition of many fluorescently labeled tyramides so that both gene targets are represented by different fluorescent signals (e.g., green Alexa $_{488}$ and red Alexa 595 ), again enabling microscopybased co-localization of the separate gene targets. Here the goal was to find the microbial "owners" of biogeochemically important genes from samples of complex communities.

Building upon these findings, phageFISH (Allers et al., 2013) was developed to more sensitively target marker genes of both cells and their infecting phages. It improved upon previous geneFISH and FISH-based methods (Hoshino and Schramm, 2010; Kawakami etal., 2010; Moraru et al., 2010) by increasing detection efficiency of phage genes from less than $40 \%$ to $98 \%$ by using more probes (up to 12 probes, 300bp each) to enable detection of a single phage gene copy within a cell. Though long probes $(\sim 800 \mathrm{bp})$ have been used to achieve similar detection efficiency (Kawakami et al., 2012), the binding specificity for naturally occuring phage targets can be affected due to high genetic variation where such long stretches of conservation are uncommon. This high sensitivity enables phageFISH to measure infection dynamics (Figure 1B) from early (single phage template) to late/bursting stage (multiple phage templates encapsulated and spread out), as demonstrated in marine podovirus-gammaproteobacterial host model system (Allers et al., 2013). Such measurements are invaluable for discerning among 
lytic, lysogenic, and chronic phage infection modes (Figure 2), and phageFISH is the only method available to do this without genetics.

For single phage-host model systems, the production of probe sets is straightforward with identification of 6-12 gene regions with similar $\% \mathrm{G}+\mathrm{C}$ and length to achieve melting temperatures that range no more than $1-2^{\circ} \mathrm{C}$. However, for environmental samples, bioinformatics is required to identify suitable areas of conservation as even core orthologous genes in viruses can be $<40 \%$ identical for 21 out of 57 tested viral taxa (Kristensen et al., 2013). Growing viral metagenomic datasets [e.g., viromes from seawater (Hurwitz and Sullivan, 2013), freshwater (Roux et al., 2012), marine sediment (Breitbart et al., 2004; Yoshida et al., 2013), and human gut (Waller et al., 2014)] should at least provide the sequence data to identify highly conserved phage gene targets suitable for phageFISH probe design. Also well-studied phage groups like T4-like myoviruses (Sullivan et al., 2010; Deng et al., 2014) and T7-like podoviruses (Labrie et al., 2013), for which "core genomes" are already identified, offer prime starting materials for phageFISH probe development and application. Pragmatically, probes must target all phages of interest with no more than 5\% mismatches to be effective (Moraru et al., 2010), which requires consideration of appropriate sub-groups to target.

In addition to probe design challenges, the use of a catalyzed reporter deposition (CARD) step limits phageFISH to at best "relative quantification." Specifically, phageFISH cannot absolutely quantify phage targets within cells where tyrosine molecules of close proximity to target-bound probes become limited. To acquire absolute quantification of per-cell phage signal, the CARD step needs to be eliminated, perhaps replaced by super-resolution microscopy to allow sensitive signal detection (Huang et al., 2010; Schermelleh et al., 2010; Vaughan et al., 2012). Finally, phageFISH is currently, relatively low throughput since only a limited number of samples on membrane filters or positive slides can be handled at a time. To increase throughput, especially for experiments comparing infection of one phage on multiple hosts or different phages on the same host, phageFISH samples could be prepared in a 96or 384-well plate format and analyzed by an automated imaging system.

\section{CONCLUSION}

These three emerging methods enable future studies to examine phage-host interaction at the single-cell level with particular strengths in accessing the uncultivated phage-host pairs in nature. Mining the viral signal from rapidly growing SAG datasets offers a high-throughput informatic approach to identify phage-host pairs and temperate phages, as well as estimate the frequency of infection in microbial populations. Complementarily, digital PCR and phageFISH utilize single-cell resolution marker gene tracking of specific phage-host pairs through space and time with strong potential for high-throughput adaptation that would allow more rapid screening and large-scale experimental tracking. While microfluidic digital PCR likely has more immediate high-throughput capability, phageFISH offers the sole ability to discriminate between infection strategies (e.g., lytic, chronic, lysogenic) through single-cell dynamic measurements. To further understand particular viral gene dynamics or the function of any viral-encoded genes, gene or protein expression studies are required during the course of infection (e.g., Lindell et al., 2007; Dammeyer et al., 2008; Thompson et al., 2011). Together these and other advances in viromics (e.g., Andrews-Pfannkoch et al., 2010; John et al., 2011; Duhaime et al., 2012; Hurwitz et al., 2013a; Culley et al., 2014), informatics (e.g., Jiang et al., 2012; Albertsen et al., 2013; Gagic et al., 2014; Hurwitz et al., 2014), and theory (e.g., Beckett and Williams, 2013; Weitz et al., 2013; Soffer et al., 2014; Thingstad et al., 2014) are transforming our ability to explore natural viral communities at the single-cell and whole population levels and increasingly in their hosts. While this review is focused on phages, relevant archaeal hosts and their viruses could also be investigated using these methods. These advances should help viral and microbial ecologists begin to develop predictive models for these critical ecological and evolutionary cogs in natural ecosystems.

\section{ACKNOWLEDGMENTS}

We thank our colleagues Mya Breitbart, Sallie Chisholm, Maureen Coleman, Jed Fuhrman, Steven Hallam, Philip Hugenholtz, Debbie Lindell, Forest Rohwer, Grieg Steward, Joshua Weitz, Mark Young, and TMPL lab members for years of engaging discussions on viral ecology methods. This publication is funded in part by the Gordon and Betty Moore Foundation grants GBMF2631, GBMF3305, and GBMF3790 to Matthew B. Sullivan.

\section{REFERENCES}

Akhter, S., Aziz, R. K., and Edwards, R. A. (2012). PhiSpy: a novel algorithm for finding prophages in bacterial genomes that combines similarity- and composition-based strategies. Nucleic Acids Res. 40:e126. doi: 10.1093/nar/gks406

Albertsen, M., Hugenholtz, P., Skarshewski, A., Nielsen, K. L., Tyson, G. W., and Nielsen, P. H. (2013). Genome sequences of rare, uncultured bacteria obtained by differential coverage binning of multiple metagenomes. Nat. Biotechnol. 31, 533-538. doi: 10.1038/nbt.2579

Allers, E., Moraru, C., Duhaime, M., Beneze, E., Solonenko, N., Barrero-Canosa, J., et al. (2013). Single-cell and population level viral infection dynamics revealed by phageFISH, a method to visualize intracellular and free viruses. Environ. Microbiol. 15:2306. doi: 10.1111/1462-2920.12100

Anantharaman, K., Duhaime, M. B., Breier, J. A., Wendt, K. A., Toner, B. M., and Dick, G. J. (2014). Sulfur oxidation genes in diverse deep-sea viruses. Science 344, 757-760. doi: 10.1126/science.1252229

Anderson, R. E., Brazelton, W. J., and Baross, J. A. (2011a). Is the genetic landscape of the deep subsurface biosphere affected by viruses? Front. Microbiol. 2:219. doi: 10.3389/fmicb.2011.00219

Anderson, R. E., Brazelton, W. J., and Baross, J. A. (2011b). Using CRISPRs as a metagenomic tool to identify microbial hosts of a diffuse flow hydrothermal vent viral assemblage. FEMS Microbiol. Ecol. 77, 120-133. doi: 10.1111/j.15746941.2011.01090.x

Andersson, A. F., and Banfield, J. F. (2008). Virus population dynamics and acquired virus resistance in natural microbial communities. Science 320, 1047-1050. doi: 10.1126/science. 1157358

Andrews-Pfannkoch, C., Fadrosh, D. W., Thorpe, J., and Williamson, S. J. (2010). Hydroxyapatite-mediated separation of double-stranded DNA, single-stranded DNA, and RNA genomes from natural viral assemblages. Appl. Environ. Microb. 76, 5039-5045. doi: 10.1128/AEM.00204-10

Ashelford, K. E., Day, M. J., and Fry, J. C. (2003). Elevated abundance of bacteriophage infecting bacteria in soil. Appl. Environ. Microbiol. 69, 285-289. doi: 10.1128/aem.69.1.285-289.2003

Baker, M. (2012). Digital PCR hits its stride. Nat. Methods 9, 541-544. doi: 10.1038/nmeth.2027

Beckett, S. J., and Williams, H. T. P. (2013). Coevolutionary diversification creates nested-modular structure in phage-bacteria interaction networks. Interface Focus 3, 20130033. doi: 10.1098/rsfs.2013.0033 
Bergh, O. (1989). High abundance of viruses found in aquatic environments. Nature 340, 467-468. doi: 10.1038/340467a0

Bossi, L., Fuentes, J. A., Mora, G., and Figueroa-Bossi, N. (2003). Prophage contribution to bacterial population dynamics. J. Bacteriol. 185, 6467-6471. doi: 10.1128/JB.185.21.6467-6471.2003

Breitbart, M., Felts, B., Kelley, S., Mahaffy, J. M., Nulton, J., Salamon, P., et al. (2004). Diversity and population structure of a near-shore marine-sediment viral community. Proc. Biol. Sci. 271, 565-574. doi: 10.1098/rspb.2003.2628

Breitbart, M., Thompson, L. R., Suttle, C. S., and Sullivan, M. B. (2007). Exploring the vast diversity of marine viruses. Oceanography 20, 353-362. doi: 10.5670/oceanog.2007.58

Broudy, T. B., and Fischetti, V. A. (2003). In vivo lysogenic conversion of ToxStreptococcus pyogenes to Tox + with lysogenic Streptococci or free phage. Infect. Immun. 71, 3782-3786. doi: 10.1128/IAI.71.7.3782-3786.2003

Brussow, H., Canchaya, C., and Hardt, W. D. (2004). Phages and the evolution of bacterial pathogens: from genomic rearrangements to lysogenic conversion. Microbiol. Mol. Biol. R. 68, 560-602. doi: 10.1128/MMBR.68.3.560-602.2004

Canchaya, C., Proux, C., Fournous, G., Bruttin, A., and Brussow, H. (2003). Prophage genomics. Microbiol. Mol. Biol. R. 67, 238-276. doi 10.1128/MMBR.67.2.238-276.2003

Catalão, M. J., Gil, F., Moniz-Pereira, J., São-José, C., and Pimentel, M. (2013). Diversity in bacterial lysis systems: bacteriophages show the way. FEMS Microbiol. Rev. 37, 554-571. doi: 10.1111/1574-6976.12006

Ceyssens, P.-J., Brabban, A., Rogge, L., Lewis, M. S., Pickard, D., Goulding, D., et al. (2010). Molecular and physiological analysis of three Pseudomonas aeruginosa phages belonging to the "N4-like viruses". Virology 405, 26-30. doi 10.1016/j.virol.2010.06.011

Culley, A. I., Mueller, J. A., Belcaid, M., Wood-Charlson, E. M., Poisson, G., and Steward, G. F. (2014). The characterization of RNA viruses in tropical seawater using targeted PCR and metagenomics. mBio 5, e01210-e01214. doi: 10.1128/mBio.01210-14

Dammeyer, T., Bagby, S. C., Sullivan, M. B., Chisholm, S. W., and FrankenbergDinkel, N. (2008). Efficient phage-mediated pigment biosynthesis in oceanic cyanobacteria. Curr. Biol. 18, 442-448. doi: 10.1016/j.cub.2008.02.067

Danovaro, R., Manini, E., and Dell'anno, A. (2002). Higher abundance of bacteria than of viruses in deep Mediterranean sediments. Appl. Environ. Microbiol. 68, 1468-1472. doi: 10.1128/AEM.68.3.1468-1472.2002

Davis, B. M., Kimsey, H. H., Chang, W., and Waldor, M. K. (1999). The Vibrio cholerae $\mathrm{O} 139$ Calcutta bacteriophage $\mathrm{CTX} \varphi$ is infectious and encodes a novel repressor. J. Bacteriol. 181, 6779-6787.

Deng, L., Gregory, A., Yilmaz, S., Poulos, B., Hugenholtz, P., and Sullivan, M. (2012). Contrasting life strategies of viruses that infect photo- and heterotrophic bacteria, as revealed by viral tagging. mBio 3, e00516-e00512. doi: 10.1128/mBio.00516-12

Deng, L., Ignacio-Espinoza, J. C., Gregory, A. C., Poulos, B. T., Weitz, J. S., Hugenholtz, P., et al. (2014). Viral tagging reveals discrete populations in Synechococcus viral genome sequence space. Nature 513, 242-245. doi: 10.1038 /nature 13459

Díaz-Muñoz, S. L., and Koskella, B. (2014). "Bacteria-phage interactions in natura environments," in Advances in Applied Microbiology, eds S. Sima and G. Geoffrey (Michael, MN: Academic Press), 135-183.

Duhaime, M. B., Deng, L., Poulos, B. T., and Sullivan, M. B. (2012). Towards quantitative metagenomics of wild viruses and other ultra-low concentration DNA samples: a rigorous assessment and optimization of the linker amplification method. Environ. Microbiol. 14, 2526-2537. doi: 10.1111/j.1462-2920.2012.02791.x

Edlin, G., Lin, L., and Kudrna, R. (1975). Lambda lysogens of E. coli reproduce more rapidly than non-lysogens. Nature 255, 735-737. doi: 10.1038/25 $5735 \mathrm{a} 0$

Fogg, P. C. M., Hynes, A. P., Digby, E., Lang, A. S., and Beatty, J. T. (2011). Characterization of a newly discovered Mu-like bacteriophage, RcapMu, in Rhodobacter capsulatus strain SB1003. Virology 421, 211-221. doi: 10.1016/j.virol.2011.09.028

Fortier, L.-C., and Sekulovic, O. (2013). Importance of prophages to evolution and virulence of bacterial pathogens. Virulence 4, 354-365. doi: 10.4161/viru. 24498

Fuhrman, J. A. (1999). Marine viruses and their biogeochemical and ecological effects. Nature 399, 541-548. doi: 10.1038/21119

Gagic, D., Maclean, P. H., Li, D., Attwood, G. T., and Moon, C. D. (2014). Improving the genetic representation of rare taxa within complex microbial communities using DNA normalization methods. Mol. Ecol. Resour. (Advance online publication). doi: 10.1111/1755-0998.12321
Hennes, K. P., and Simon, M. (1995). Significance of bacteriophages for controlling bacterioplankton growth in a mesotrophic lake. Appl. Environ. Microb. 61, 333340. doi: 10.1111/1755-0998.12321

Hindson, B. J., Ness, K. D., Masquelier, D. A., Belgrader, P., Heredia, N. J., Makarewicz, A. J., et al. (2011). High-throughput droplet digital PCR system for absolute quantitation of DNA copy number. Anal. Chem. 83, 8604-8610. doi: $10.1021 / \mathrm{ac} 202028 \mathrm{~g}$

Hitch, G., Pratten, J., and Taylor, P. W. (2004). Isolation of bacteriophages from the oral cavity. Lett. Appl. Microbiol. 39, 215-219. doi: 10.1111/j.1472765X.2004.01565.X

Holmfeldt, K., Howard-Varona, C., Solonenko, N., and Sullivan, M. B. (2014). Contrasting genomic patterns and infection strategies of two co-existing Bacteroidetes podovirus genera. Environ. Microbiol. 16, 2501-2513. doi: 10.1111/14622920.12391

Holmfeldt, K., Solonenko, N., Shah, M., Corrier, K., Riemann, L., Verberkmoes, N. C., etal. (2013). Twelve previously unknown phage genera are ubiquitous in global oceans. Proc. Natl. Acad. Sci. U.S.A. 110, 12798-12803. doi: $10.1073 /$ pnas. 1305956110

Hoshino, T., and Schramm, A. (2010). Detection of denitrification genes by in situ rolling circle amplification-fluorescence in situ hybridization to link metabolic potential with identity inside bacterial cells. Environ. Microbiol. 12, 2508-2517. doi: 10.1111/j.1462-2920.2010.02224.x

Huang, B., Babcock, H., and Zhuang, X. (2010). Breaking the diffraction barrier: super-resolution imaging of cells. Cell 143, 1047-1058. doi: 10.1016/j.cell.2010.12.002

Hurwitz, B. L., Deng, L., Poulos, B. T., and Sullivan, M. B. (2013a). Evaluation of methods to concentrate and purify ocean virus communities through comparative, replicated metagenomics. Environ. Microbiol. 15, 1428-1440. doi: 10.1111/j.1462-2920.2012.02836.x

Hurwitz, B. L., Hallam, S. J., and Sullivan, M. B. (2013b). Metabolic reprogramming by viruses in the sunlit and dark ocean. Genome Biol. 14:R123. doi: 10.1186/gb2013-14-11-r123

Hurwitz, B. L., and Sullivan, M. B. (2013). The Pacific Ocean virome (POV): a marine viral metagenomic dataset and associated protein clusters for quantitative viral ecology. PLoS ONE 8:e57355. doi: 10.1371/journal.pone. 0057355

Hurwitz, B. L., Westveld, A. H., Brum, J. R., and Sullivan, M. B. (2014). Modeling ecological drivers in marine viral communities using comparative metagenomics and network analyses. Proc. Natl. Acad. Sci. U.S.A. 111, 10714-10719. doi: 10.1073/pnas.1319778111

Jiang, B., Song, K., Ren, J., Deng, M., Sun, F., and Zhang, X. (2012). Comparison of metagenomic samples using sequence signatures. BMC Genom. 13:730. doi: 10.1186/1471-2164-13-730

Jiang, S. C., and Paul, J. H. (1998). Significance of lysogeny in the marine environment: studies with isolates and a model of lysogenic phage production. Microb. Ecol. 35, 235-243. doi: 10.1007/s002489900079

John, S. G., Mendez, C. B., Deng, L., Poulos, B., Kauffman, A. K. M., Kern, S., et al. (2011). A simple and efficient method for concentration of ocean viruses by chemical flocculation. Environ. Microbiol. Rep. 3, 195-202. doi: 10.1111/j.17582229.2010.00208 x

Jones, M., Williams, J., Gärtner, K., Phillips, R., Hurst, J., and Frater, J. (2014). Low copy target detection by Droplet Digital PCR through application of a novel open access bioinformatic pipeline, 'definetherain'. J. Virol. Methods 202, 46-53. doi: 10.1016/j.jviromet.2014.02.020

Jover, L. F., Effler, T. C., Buchan, A., Wilhelm, S. W., and Weitz, J. S. (2014). The elemental composition of virus particles: implications for marine biogeochemical cycles. Nat. Rev. Microbiol. 12, 519-528. doi: 10.1038/nrmicro3289

Kang, I., Oh, H.-M., Kang, D., and Cho, J.-C. (2013). Genome of a SAR116 bacteriophage shows the prevalence of this phage type in the oceans. Proc. Natl. Acad. Sci. U.S.A. 110, 12343-12348. doi: 10.1073/pnas.1219 930110

Kawakami, S., Hasegawa, T., Imachi, H., Yamaguchi, T., Harada, H., Ohashi, A., et al. (2012). Detection of single-copy functional genes in prokaryotic cells by two-pass TSA-FISH with polynucleotide probes. J. Microbiol. Methods 88, 218-223. doi: 10.1016/j.mimet.2011.11.014

Kawakami, S., Kubota, K., Imachi, H., Yamaguchi, T., Harada, H., and Ohashi, A. (2010). Detection of single copy genes by two-pass tyramide signal amplification fluorescence in situ hybridization (two-pass TSA-FISH) with single oligonucleotide probes. Microbes Environ. 25, 15-21. doi: 10.1264/jsme2.ME09180 
Kinde, I., Wu, J., Papadopoulos, N., Kinzler, K. W., and Vogelstein, B. (2011). Detection and quantification of rare mutations with massively parallel sequencing. Proc. Natl. Acad. Sci. U.S.A. 108, 9530-9535. doi: 10.1073/pnas.1105422108

Kristensen, D. M., Waller, A. S., Yamada, T., Bork, P., Mushegian, A. R., and Koonin, E. V. (2013). Orthologous gene clusters and taxon signature genes for viruses of prokaryotes. J. Bacteriol. 195, 941-950. doi: 10.1128/jb.01801-12

Labrie, S. J., Frois-Moniz, K., Osburne, M. S., Kelly, L., Roggensack, S. E., Sullivan, M. B., et al. (2013). Genomes of marine cyanopodoviruses reveal multiple origins of diversity. Environ. Microbiol. 15, 1356-1376. doi: 10.1111/1462-2920.12053

Lasken, R. S. (2012). Genomic sequencing of uncultured microorganisms from single cells. Nat. Rev. Micro. 10, 631-640. doi: 10.1038/nrmicro2857

Letarov, A., and Kulikov, E. (2009). The bacteriophages in human- and animal body-associated microbial communities. J. Appl. Microbiol. 107, 1-13. doi: 10.1111/j.1365-2672.2009.04143.x

Lindell, D., Jaffe, J. D., Coleman, M. L., Futschik, M. E., Axmann, I. M., Rector, T., et al. (2007). Genome-wide expression dynamics of a marine virus and hos reveal features of co-evolution. Nature 449, 83-86. doi: 10.1038/nature06130

Lindell, D., Sullivan, M. B., Johnson, Z. I., Tolonen, A. C., Rohwer, F., and Chisholm, S. W. (2004). Transfer of photosynthesis genes to and from Prochlorococcus viruses. Proc. Natl. Acad. Sci. U.S.A. 101, 11013-11018. doi: 10.1073/pnas.0401526101

Little, J. W. (2005). "Lysogeny, prophage induction, and lysogenic conversion," in Phages their Role in Bacterial Pathogenesis and Biotechnology, eds M. K. Waldor, D. I. Friedman, and S. Adhya (Washington, DC: ASM Press), 37-54.

Lood, R., and Collin, M. (2011). Characterization and genome sequencing of two Propionibacterium acnes phages displaying pseudolysogeny. BMC Genom. 12:198. doi: 10.1186/1471-2164-12-198

Lu, J., Chen, F., and Hodson, R. E. (2001). Distribution, isolation, host specificity, and diversity of cyanophages infecting marine Synechococcus spp. in river estuaries. Appl. Environ. Microbiol. 67, 3285-3290. doi: 10.1128/AEM.67.7.32853290.2001

Macaulay, I. C., and Voet, T. (2014). Single cell genomics: advances and future perspectives. PLoS Genet. 10:e1004126. doi: 10.1371/journal.pgen.1004126

Mann, N. H., Cook, A., Millard, A., Bailey, S., and Clokie, M. (2003). Marine ecosystems: bacterial photosynthesis genes in a virus. Nature 424, 741-741. doi: $10.1038 / 424741 \mathrm{a}$

Marcy, Y., Ouverney, C., Bik, E. M., Lösekann, T., Ivanova, N., Martin, H. G., et al. (2007). Dissecting biological "dark matter" with single-cell genetic analysis of rare and uncultivated TM7 microbes from the human mouth. Proc. Natl. Acad. Sci. U.S.A. 104, 11889-11894. doi: 10.1073/pnas.0704662104

Mizuno, C. M., Rodriguez-Valera, F., Kimes, N. E., and Ghai, R. (2013). Expanding the marine virosphere using metagenomics. PLoS Genet. 9:e1003987. doi: 10.1371/journal.pgen.1003987

Mokrousov, I. (2009). Corynebacterium diphtheriae: genome diversity, population structure and genotyping perspectives. Infect. Genet. Evol. 9, 1-15. doi: 10.1016/j.meegid.2008.09.011

Moraru, C., Lam, P., Fuchs, B. M., Kuypers, M. M., and Amann, R. (2010). GeneFISH - an in situ technique for linking gene presence and cell identity in environmental microorganisms. Environ. Microbiol. 12, 3057-3073. doi: 10.1111/j.1462-2920.2010.02281.x

Ottesen, E. A., Hong, J. W., Quake, S. R., and Leadbetter, J. R. (2006). Microfluidic digital PCR enables multigene analysis of individual environmental bacteria. Science 314, 1464-1467. doi: 10.1126/science. 1131370

Paul, J. H. (2008). Prophages in marine bacteria: dangerous molecular time bombs or the key to survival in the seas? ISME J. 2, 579-589. doi: 10.1038/ismej.2008.35

Rappe, M. S., and Giovannoni, S. J. (2003). The uncultured microbial majority. Annu. Rev. Microbiol. 57, 369-394. doi: 10.1146/annurev.micro.57.030502.090759

Reyes, A., Wu, M., Mcnulty, N. P., Rohwer, F. L., and Gordon, J. I. (2013). Gnotobiotic mouse model of phage-bacterial host dynamics in the human gut. Proc. Natl. Acad. Sci. U.S.A. 110, 20236-20241. doi: 10.1073/pnas.1319470110

Rinke, C., Schwientek, P., Sczyrba, A., Ivanova, N. N., Anderson, I. J., Cheng, J. F., et al. (2013). Insights into the phylogeny and coding potential of microbial dark matter. Nature 499, 431-437. doi: 10.1038/nature12352

Rose, T. M., Henikoff, J. G., and Henikoff, S. (2003). CODEHOP (consensusdegenerate hybrid oligonucleotide primer) PCR primer design. Nucleic Acids Res. 31, 3763-3766. doi: 10.1093/nar/gkg524

Roux, S., Enault, F., Robin, A., Ravet, V., Personnic, S., Theil, S., et al. (2012). Assessing the diversity and specificity of two freshwater viral communities through metagenomics. PLoS ONE 7:e33641. doi: 10.1371/journal.pone.0033641
Roux, S., Hawley, A. K., Torres Beltran, M., Scofield, M., Schwientek, P., Stepanauskas, R., et al. (2014). Ecology and evolution of viruses infecting uncultivated SUP05 bacteria as revealed by single-cell- and meta-genomics. Elife 3:e03125. doi: 10.7554/eLife.03125

Salifu, S. P., Casey, S. A. C., and Foley, S. (2013). Isolation and characterization of soilborne virulent bacteriophages infecting the pathogen Rhodococcus equi. J. Appl. Microbiol. 114, 1625-1633. doi: 10.1111/jam.12194

Schermelleh, L., Heintzmann, R., and Leonhardt, H. (2010). A guide to super-resolution fluorescence microscopy. J. Cell Biol. 190, 165-175. doi: 10.1083/jcb.201002018

Sharon, I., Alperovitch, A., Rohwer, F., Haynes, M., Glaser, F., Atamna-Ismaeel, N., et al. (2009). Photosystem I gene cassettes are present in marine virus genomes. Nature 461, 258-262. doi: 10.1038/nature08284

Shelford, E. J., Middelboe, M., Møller, E. F., and Suttle, C. A. (2012). Virus-driven nitrogen cycling enhances phytoplankton growth. Aquat. Microb. Ecol. 66, 41-46. doi: 10.3354/ame01553

Smith, C. J., and Osborn, A. M. (2009). Advantages and limitations of quantitative PCR (Q-PCR)-based approaches in microbial ecology. FEMS Microbiol. Ecol. 67, 6-20. doi: 10.1111/j.1574-6941.2008.00629.x

Soffer, N., Zaneveld, J., and Vega Thurber, R. (2014). Phage-bacteria network analysis and its implication for the understanding of coral disease. Environ. Microbiol. (Advance online publication). doi: 10.1111/1462-2920.12553

Stern, A., Mick, E., Tirosh, I., Sagy, O., and Sorek, R. (2012). CRISPR targeting reveals a reservoir of common phages associated with the human gut microbiome. Genome Res. 22, 1985-1994. doi: 10.1101/gr.138297.112

Sullivan, M. B., Huang, K. H., Ignacio-Espinoza, J. C., Berlin, A., Kelly, L., Weigele, P. R., etal. (2010). Genomic analysis of oceanic cyanobacterial myoviruses compared to T4-like myoviruses from diverse hosts and environments. Environ. Microbiol. 12, 3035-3056. doi: 10.1111/j.1462-2920.2010. 02280.x

Sullivan, M. B., Lindell, D., Lee, J. A., Thompson, L. R., Bielawski, J. P., and Chisholm, S. W. (2006). Prevalence and evolution of core photosystem II genes in marine cyanobacterial viruses and their hosts. PLoS Biol. 4:e234. doi: 10.1371/journal.pbio.0040234

Sullivan, M. B., Waterbury, J. B., and Chisholm, S. W. (2003). Cyanophages infecting the oceanic cyanobacterium Prochlorococcus. Nature 424, 1047-1051. doi: 10.1038/nature01929

Suttle, C. A., and Chan, A. M. (1993). Marine cyanophages infecting oceanic and coastal strains of Synechococcus: abundance, morphology, cross-infectivity and growth characteristics. Mar. Ecol. Prog. Ser. 92, 99-109. doi: 10.3354/meps0 92099

Tadmor, A. D., Ottesen, E. A., Leadbetter, J. R., and Phillips, R. (2011). Probing individual environmental bacteria for viruses by using microfluidic digital PCR. Science 333, 58-62. doi: 10.1126/science.1200758

Thingstad, T. F., Våge, S., Storesund, J. E., Sandaa, R.-A., and Giske, J. (2014). A theoretical analysis of how strain-specific viruses can control microbial species diversity. Proc. Natl. Acad. Sci. U.S.A. 111, 7813-7818. doi: 10.1073/pnas.1400909111

Thompson, L. R., Zeng, Q., Kelly, L., Huang, K. H., Singer, A. U., Stubbe, J., et al. (2011). Phage auxiliary metabolic genes and the redirection of cyanobacterial host carbon metabolism. Proc. Natl. Acad. Sci. U.S.A. 108, e757-e764. doi: 10.1073/pnas. 1102164108

Vaughan, J. C., Jia, S., and Zhuang, X. (2012). Ultrabright photoactivatable fluorophores created by reductive caging. Nat. Methods 9, 1181-1184. doi: 10.1038/nmeth. 2214

Vogelstein, B., and Kinzler, K. W. (1999). Digital PCR. Proc. Natl. Acad. Sci. U.S.A. 96, 9236-9241. doi: 10.1073/pnas.96.16.9236

Wagner, P. L., and Waldor, M. K. (2002). Bacteriophage control of bacterial virulence. Infect. Immun. 70, 3985-3993. doi: 10.1128/IAI.70.8.3985-3993.2002

Waller, A. S., Yamada, T., Kristensen, D. M., Kultima, J. R., Sunagawa, S., Koonin, E. V., et al. (2014). Classification and quantification of bacteriophage taxa in human gut metagenomes. ISME J. 8, 1391-1402. doi: 10.1038/ismej. 2014.30

Wang, X., Kim, Y., Ma, Q., Hong, S. H., Pokusaeva, K., Sturino, J. M., et al. (2010). Cryptic prophages help bacteria cope with adverse environments. Nat. Commun. 1:147. doi: $10.1038 /$ ncomms 1146

Weinbauer, M. G. (2004). Ecology of prokaryotic viruses. FEMS Microbiol. Rev. 28, 127-181. doi: 10.1016/j.femsre.2003.08.001 
Weinberger, A. D., Sun, C. L., Pluciñski, M. M., Denef, V. J., Thomas, B. C., Horvath, P., et al. (2012). Persisting viral sequences shape microbial CRISPRbased immunity. PLoS Comput. Biol. 8:e1002475. doi: 10.1371/journal.pcbi. 1002475

Weitz, J. S., Poisot, T., Meyer, J. R., Flores, C. O., Valverde, S., Sullivan, M. B., et al. (2013). Phage-bacteria infection networks. Trends Microbiol. 21, 82-91. doi: 10.1016/j.tim.2012.11.003

Whitman, W. B., Coleman, D. C., and Wiebe, W. J. (1998). Prokaryotes: the unseen majority. Proc. Natl. Acad. Sci. U.S.A. 95, 6578-6583. doi 10.1073/pnas.95.12.6578

Willner, D., Furlan, M., Haynes, M., Schmieder, R., Angly, F. E., Silva, J., et al. (2009). Metagenomic analysis of respiratory tract DNA viral communities in cystic fibrosis and non-cystic fibrosis individuals. PLoS ONE 4:e7370. doi: 10.1371/journal.pone.0007370

Wittmann, J., Dreiseikelmann, B., Rohde, M., Meier-Kolthoff, J., Bunk, B., and Rohde, C. (2014). First genome sequences of Achromobacter phages reveal new members of the N4 family. Virol. J. 11:14. doi: 10.1186/1743422X-11-14

Wommack, K. E., and Colwell, R. R. (2000). Virioplankton: viruses in aquatic ecosystems. Microbiol. Mol. Biol. R. 64, 69-114. doi: 10.1128/MMBR.64.1.69114.2000

Wright, J. J., Konwar, K. M., and Hallam, S. J. (2012). Microbial ecology of expanding oxygen minimum zones. Nat. Rev. Microbiol. 10, 381-394. doi: 10.1038/nrmicro2778

Yoon, H. S., Price, D. C., Stepanauskas, R., Rajah, V. D., Sieracki, M. E., Wilson, W. H., et al. (2011). Single-cell genomics reveals organismal interactions in uncultivated marine protists. Science 332, 714-717. doi: 10.1126/science.1203163
Yoshida, M., Takaki, Y., Eitoku, M., Nunoura, T., and Takai, K. (2013). Metagenomic analysis of viral communities in (hado)pelagic sediments. PLoS ONE 8:e57271. doi: 10.1371/journal.pone.0057271

Young, R. (1992). Bacteriophage lysis: mechanism and regulation. Microbiol. Rev. $56,430-481$.

Zare, R. N., and Kim, S. (2010). Microfluidic platforms for single-cell analysis. Annu. Rev. Biomed. Eng. 12, 187-201. doi: 10.1146/annurev-bioeng-070909-105238

Zhao, Y., Temperton, B., Thrash, J. C., Schwalbach, M. S., Vergin, K. L., Landry, Z. C., et al. (2013). Abundant SAR11 viruses in the ocean. Nature 494, 357-360. doi: $10.1038 /$ nature 11921

Conflict of Interest Statement: The authors declare that the research was conducted in the absence of any commercial or financial relationships that could be construed as a potential conflict of interest.

Received: 24 October 2014; accepted: 02 December 2014; published online: 23 December 2014.

Citation: Dang VT and Sullivan MB (2014) Emerging methods to study bacteriophage infection at the single-cell level. Front. Microbiol. 5:724. doi: 10.3389/fmicb.2014.00724 This article was submitted to Microbial Physiology and Metabolism, a section of the journal Frontiers in Microbiology.

Copyright (C) 2014 Dang and Sullivan. This is an open-access article distributed under the terms of the Creative Commons Attribution License (CC BY). The use, distribution or reproduction in other forums is permitted, provided the original author(s) or licensor are credited and that the original publication in this journal is cited, in accordance with accepted academic practice. No use, distribution or reproduction is permitted which does not comply with these terms. 